\title{
FAMÍLIAS DAS ARMAS: REPRODUÇÃO FAMILIAR E CAR- REIRAS NO EXÉRCITO BRASILEIRO (1850-1930)
}

\section{ARMY FAMILIES: FAMILY REPRODUCTION AND CAREERS IN THE BRAZILIAN ARMY (1850-1930)}

\author{
Ernesto Seidl*
}

De fato, a família tem um papel determinante na manutenção da ordem social, na reprodução não apenas biológica, mas social, isto é, na reprodução da estrutura do espaço social e das relações e bens sociais. Ela é um dos lugares por excelência de acumulação de capital sob seus diferentes tipos e de sua transmissão entre as gerações: ela resguarda sua unidade pela transmissão e para a transmissão, para poder transmitir e porque ela pode transmitir. (BOURDIEU, 1996, p. 131)

\section{Introdução}

A observação de sobrenomes que se repetem ao longo de décadas nas listas do alto oficialato do Exército brasileiro não constitui nenhuma surpresa sociológica. 0 mesmo ocorre nas forças armadas de diversos outros países e também no interior de muitas outras instituições e de profissões variadas $^{1}$. A diplomacia, a magistratura, a Igreja Católica e a medicina são apenas alguns exemplos mais notórios. Mas seria ainda preciso lembrar de tantos outros ofícios, de maior ou menor prestígio social, nos quais gerações de famílias se especializam, às vezes por séculos ${ }^{2}$, e em torno dos quais constroem reputações.

A lógica que relaciona grupos familiares a certas instituições e carreiras se apresenta, portanto, em muitas esferas, e desfruta

\footnotetext{
* Professor do Departamento de Sociologia e Ciência Política da Universidade Federal de Santa Catarina - UFSC- (Florianópolis/SC/Brasil). Doutor em Ciência Política pela UFRGS. Bolsista de Produtividade do CNPq. E-mail: ernestoseidl@gmail.com.

1. Sou muito grato a Mike Phillips, do King's College London, por observações sobre a histórica reprodução de famílias no interior do Exército dos Estados Unidos e por vasto material bibliográfico que me alcançou a respeito.

2. É o caso de muitas atividades de comércio, de artesania, fınanças, artes - ofícios que se afirmaram socialmente ao longo da Idade Média, organizados em corporações, guildas e mesteiras (MARTINS, 2008).
} 
de forte legitimidade social. 0 fenômeno de famílias "de tradição" na medicina, na engenharia, no Exército, na política, no Direito, nas artes, esportes - e, sublinhe-se bem, em carreiras do Estado -, de modo algum é concebido como algo próprio a um período anterior à ideologia do mérito ou uma característica de sociedades arcaicas. Muito pelo contrário, está fixado nas representações cotidianas justamente como indicação de um traço hereditário ligado a talento, habilidade, vocação e pendor. Logo, a uma competência e, afinal de contas, a um mérito. Ou seja, cada novo membro da família que abraça uma carreira o faz de modo coerente com o destino do grupo e, ao se tornar reconhecido - "filho de peixe, peixinho é", reza um ditado muito difundido -, apenas confirma as expectativas nele depositadas, e reforça a sociodiceia familiar ${ }^{3}$.

A análise da composição social do alto oficialato brasileiro até as primeiras décadas da República mostra elevado grau de endogenia no recrutamento daquela elite. Revela ainda número considerável de membros de grupos familiares cujos nomes se tornaram indissociáveis da própria instituição militar. Portanto, indissociáveis também da carreira, da profissão e, por consequência, dos atributos e competências que, ao longo do tempo, forjaram represen- tações dominantes sobre as atividades militares: bravura/heroísmo, disciplina e destreza, antes de tudo, e, mais recentemente, desempenho escolar e intelectual.

Também certas regiões do país, com destaque ao estado do Rio Grande do Sul, são conhecidas no senso comum e na historiografıa militar como "terra de militares", "berço de generais”. Tanto o número de altos oficiais oriundos daquele estado quanto a presença de militares gaúchos em postos políticos de alto escalão ${ }^{4}$ têm reforçado a imagem de uma região "vocacionada para as armas", ou aquilo que Joseph Love chamou de "mito da inclinação gaúcha para a vida militar” (LOVE, 1975, p. 124).

Este artigo discute as condições de constituição de uma fração das elites militares com base no estudo de grupos familiares cuja existência, reprodução e notabilização, ao longo de gerações, dependeram amplamente do Exército e de outras estruturas do Estado. 0 acesso privilegiado à carreira e a valorização institucional de atributos angariados por esses grupos revelam o alto ajuste entre a oferta de oportunidades a certas frações sociais no interior do serviço estatal e as estratégias de reprodução ${ }^{5}$ que lograram acionar, perpetuando assim a própria instituição. A análise dá atenção especial aos condicionantes históricos de estrutu-

3. Para ficar apenas no universo da política, sugiro consulta aos trabalhos de Lewin (1993) e de Grill (2007; 2008).

4. É extensa a lista de oficiais nascidos no estado do Rio Grande do Sul, com visibilidade ao longo do século XX e até o presente. Para citar uma pequena parte, dos cinco presidentes militares do período autoritário (1964-1985), três eram gaúchos. 0 mesmo número aparece entre os oito últimos comandantes do Exército Nacional (1985-2019), incluindo o atual, general Edson Leal Pujol, nascido em Dom Pedrito. 0 atual vice-presidente da República, general da reserva Antonio Hamilton Martins Mourão, e o ex-Ministro-Chefe do Gabinete de Segurança Institucional do governo interino de Michel Temer (2016-2019), general Sérgio Etchegoyen, também são naturais desse estado.

5. Estratégias de reprodução social são definidas por Bourdieu (1994) como um conjunto de práticas pelas quais os indivíduos ou grupos de indivíduos tendem, de modo consciente ou inconsciente, a manter ou melhorar sua posição na estrutura social. Entre elas se destacam as estratégias sucessorais, econômicas, educativas, matrimoniais e biológicas. 
ração do Estado no período e ao peso das estratégias matrimoniais e de notabilização eficazes na construção de patrimônios sociais erigidos em torno da ideia de "serviço ao Exército brasileiro".

À semelhança de outros espaços sociais ou domínios em processo de institucionalização na sociedade brasileira, ao longo do Império e início da República, aquilo que se pode chamar de domínio militar ${ }^{5}$, ou de atividades ligadas à guerra, apresentava princípios de organização e de regulação de contornos pouco definidos. Antes de mais nada, é preciso ter clareza de que a invenção do militar contemporâneo, enquadrado pela instituição, isto é, o especialista, técnico, disciplinado e que se sente membro de uma corporação, ainda era objeto de discussão no Brasil da década de 1930 (CASTRO, 1990; McCANN, 2007). Portanto, a ideia de uma instituição profissionalizada, com formação própria e rigorosa, de uma carreira militar ${ }^{7}$, faz pouco sentido para grande parte do período considerado nesta análise. 0 que nem de longe significa - muito pelo contrário! -, que discussões intensas em torno daqueles ideais, e também medidas concretas, não tenham ocorrido e servido como móveis de disputa candentes entre diferentes atores.
Até meados do século XIX, o Exército brasileiro funcionava nos moldes patrimonialistas das forças coloniais portuguesas. Recrutados em bases personalistas, os oficiais eram, em sua grande parte, membros da nobreza lusa, filhos de oficiais superiores e sem formação específica ou treinamento. Tampouco se dedicavam de forma exclusiva à instituição, viviam arregimentados ou afastados de outras atividades. Pelo contrário, vários eram proprietários de terras e de outros bens (gados, escravos, engenhos), mobilizavam-se sobretudo em períodos de conflitos e eram muito ativos na política em cargos eletivos e de administração, a serviço da Coroa. 0 padrão de ascensão na hierarquia ${ }^{8}$ seguia os princípios gerais de distribuição de privilégios, distinção e poder na sociedade do período, como demonstrado por José Murilo de Carvalho (1996). Como regra, beneficiavam indivíduos de origem mais elevada e de maior proximidade aos círculos de poder, aqueles com maior folha de serviços prestados à Coroa (e a outras autoridades políticas) e maior demonstração de fidelidade ${ }^{9}$.

0 processo de reorganização e de profissionalização do Exército brasileiro, cujo ponto de partida costuma ser situado a partir de 1850 (CASTRO, 1995, 2002; SCHULZ, 1977,

6. Para uma discussão bem fundamentada sobre as vantagens do uso da noção de "domínio" em configurações como a brasileira, sugiro o trabalho de Grill \&t Reis (2018).

7. 0 emprego da expressão carreira ao longo deste trabalho não implica, como se pretende demonstrar, a existência de uma esfera profissional militar relativamente autônoma, especializada ou definida por regras claras e objetivadas. Sobre o uso dessa noção em estudos sobre elites, consultar Grill \& Reis (2018).

8. Na tipologia definida por Souza (2004, p. 171-175) para caracterizar a heterogeneidade dos generais da geração de 1840 (“combatentes”, “técnicos” e "administradores”), os “administradores” não contavam com formação acadêmica nem atuação militar expressiva. Alocados em cargos de administração real, muitos inclusive serviram em "funções completamente alheias ao Exército".

9. Como nota Bourdieu (2014, p. 351-354), o Estado dinástico depende estruturalmente da lógica familiar para funcionar e para se reproduzir. Numa configuração pré ou protoburocrática, o princípio que orienta a distribuição de postos e serviços de Estado segue a lógica do pertencimento familiar (nobreza) e da proximidade à Coroa. 
1994; SOUZA, 2004), foi lento e se estendeu República adentro. Assim como sucessivas regulamentações criadas em nome da meritocracia, a lei que atrelava a promoção no oficialato ao critério de antiguidade e de mérito, exigindo formação acadêmica como pré-requisito, impactou de modo desigual a esfera militar ${ }^{10}$. Embora a crescente normativização da instituição tenha dado novas feições à carreira e criado maiores chances de ascensão a indivíduos mais dependentes de desempenho escolar e de habilidades técnicas, o alto oficialato continuou a ser destino muito mais provável aos que desfrutavam de uma "boa entrada" na carreira: filhos de oficiais superiores ou de notáveis, de nobres e de grandes proprietários.

A partir do final do Império, e progressivamente à medida que a instituição se fechava como universo mais profissionalizado, a carreira se tornou menos atrativa aos descendentes dos grupos dominantes tradicionais. Tanto as exigências de formação quanto a perda relativa de prestígio social da atividade, cada vez mais restrita a um universo específico e distante dos atributos de poder político, econômico e de notabilidade social, contribuíram para uma atração maior junto aos próprios filhos de militares.
Assim, a forte endogenia no recrutamento do alto oficialato, que atravessa todo Império, é mantida na República. Entre os generais de 1822-1860, cerca de 60\% eram filhos de oficiais superiores, percentual que cresce para 66\% no intervalo 1861-1889. Mais de $3 / 4$ dos generais do período 18901930 eram filhos de oficiais - a maioria, subalternos (43\% do total conhecido). Essa maior presença de filhos de oficiais de patentes inferiores é que constitui novidade ${ }^{11}$.

É preciso notar que a presença de grupos familiares ligados ao Exército no Brasil - que se reproduzem em bases inter e intrageracionais -, não é algo distante no tempo. Com dados sobre o oficialato dos anos 1960 e 1970, Barros (2018) mostra que cerca de $4,5 \%$ dos oficiais provinham de famílias com ao menos dois membros na ativa durante aquele período. No entanto, como ressalva o autor, embora o percentual não seja expressivo por si só, tende a sê-lo quando se considera que "a existência de um parente na ativa (e particularmente de uma geração superior) pode ajudar na progressão profissional de outro" (p. 189). E isso "simplesmente porque possuir um parente no serviço ativo tende a gerar mais 'exposição' ao outro”, tendo como ganhos

10. A exigência de um curso para promoção na carreira, introduzida em 1850, não pode ser interpretada como adoção do mérito escolar no Exército e "abertura da carreira ao talento", como acreditou Schulz (1994), autor de trabalho clássico sobre o Exército no período. Embora, no longo prazo, a expansão do sistema escolar tenha facilitado a ascensão de indivíduos de origens sociais menos privilegiadas, são fartas as evidências de que os princípios de hierarquização do espaço militar continuaram a favorecer os melhor dotados em capital familiar e em relações pessoais. Boas notas, demonstração de disciplina e de bravura raramente bastariam para a promoção dos não herdeiros. A esses, por outro lado, se multiplicavam as exigências de investimento em relações personalizadas e em adesão ideológica como mola para os ranques de maior poder e prestígio (SEIDL, 2008).

11. Os dados sobre origem social dos alunos da Academia de Agulhas Negras (AMAN) - instituição de ensino superior responsável pela formação dos oficiais de carreira do Exército - apontam predomínio de filhos de civis até em torno dos anos 1980, a partir de quando se vê equilíbrio. As informações disponíves sobre as patentes dos pais oficiais entre os anos 1970 e 1990 mostram amplo predomínio (acima de 70\%) de oficiais subalternos e praças (CASTRO, 1993). 
possíveis, Barros aponta, a "obtenção de maiores comissões”, “o casamento com a filha de um superior (e, nesse caso, também com a filha de um colega do parente de geração superior)" e a entrada facilitada "em uma das 'panelinhas' etc” ${ }^{12}$.

De fato, ao lado da antiguidade do vínculo familiar com a instituição, a extensão e a qualidade do cabedal de relações acumuladas no seio do Exército - como em qualquer instituição, a exemplo da Igreja, das carreiras jurídicas, da política - representam ativo dos mais importantes, mas, como sabido, disponível somente para frações reduzidas do contingente institucional. No caso dos grupos familiares do Rio Grande do Sul que examinamos, o estudo das condições históricas de acúmulo e transmissão desses recursos, que serviram de base e se mesclaram com outros recursos, permite que se vislumbrem com certa plasticidade os mecanismos de seleção e os critérios de hierarquização concretos que regulavam o domínio militar. Entre eles, o favoritismo apoiado em relações de parentesco e de parentela ${ }^{13}$, amizade e afinidades políticas aparecem como ingrediente fundamental.

\section{Uma vocação hereditária? As "famílias das armas" no extremo sul}

Um dos aspectos centrais a que se prende o fenômeno da reprodução de grupos familiares no interior do Exército no Rio Grande do Sul são as condições peculiares de formação daquele espaço social ao longo do “ciclo pastoril-militar” (FÉLIX, 1987). Como mostra a literatura sobre a formação do extremo sul, em especial do espaço da campanha gaúcha (CARDOSO, 1967; FARINATTI, 2009; GARCIA, 2005; NEUMANN, 2004; OSÓRIO, 1990; REICHEL, 2006), até o século XIX a conexão estreita entre ocupação da terra e imperativos de ordem militar e geopolítica colocados à Coroa portuguesa favoreceu a criação de uma estrutura social em que a figura do militar-estancieiro tinha posição dominante e inquestionável.

Beneficiados pela doação de vastas porções de terras que permitiam a criação extensiva de gado, munidos de peões e armamentos, os estancieiros cumpriam tarefas de defesa de territórios mal demarcados - o que, em boa medida, significava garantir a posse de suas próprias terras. Partes desses terratenentes integravam também corpos de milícias, cujos membros oficiais tinham seu recrutamento "entre os homens brancos, sem mesclas, que fossem proprietários rurais ou estabelecidos em algum ramo do comércio" (FERREIRA FILHO, apud BARBOSA, 1983, p. 65). Muitos também apresentavam patentes do Exército regular português, e entre aqueles de melhor posição hierárquica saíam os aquinhoados com porções mais abastadas de terra.

Numa confıguração de baixa institucionalização do poder político e administrativo na região, as relações entre os militares-es-

12. Além da importância da intervenção do parentesco em situações formais e institucionais, Eric Wolf (1980) chama atenção para a centralidade das cliques e de grupos informais similares no funcionamento de instituições burocráticas como indústrias ou exércitos.

13. Parentela é aqui entendida como sinômimo de "família extensa" ou "grupo familiar amplo", como tratado por Lewin (1993). A parentela engloba o grupo de descendência bilateral, inclui ascendentes maternos e paternos e descendentes de várias gerações. Grande número de indivíduos não consanguíneos - e isso é central - também podem vir a integrar a família pelo casamento e pelo compadrio, ou por outras relações mais amplas de reconhecimento social, como a amizade política. 
tancieiros e aquelas atividades se estabeleceram numa sobreposição do poder fundado na propriedade e nos recursos excluviso das esferas propriamente governamentais de administração. Cabe aqui retomar passagem de Saint-Hilaire sobre o poder e o papel desses militares-estancieiros: "não há lugar em que os magistrados e os funcionários civis gozem de menos importância (...). Todos evitam as formalidades judiciárias e é ao general que entregam a decisão de quase todas as questões" (SAINT-HILAIRE, apud BENTO, 1994, p. 19).

A notoriedade e o prestígio acumulados por esses personagens do "mundo da estância” (GRIJÓ, 1998) explicam, em grande medida, o alto grau de imbricação de certas linhagens familiares com o domínio das armas no extremo sul do País. Em uma sociedade estruturada em tais bases, as possibilidades de acúmulo e manutenção de um capital simbólico objetivado em um "nome" eram redobradas pelas chances de reprodução no interior de estruturas de Estado, como o Exército e a Guarda Nacional (criada em 1831 e extinta em 1922).
De fato, muitos dos descendentes de famílias oriundas desse "mundo da estância", cujos ancestrais desenvolveram um "nome de respeito" ligado a atividades bélicas e a um poder local ${ }^{14}$, com o passar do tempo foram incorporados àquelas instituições. Vindo a ocupar postos de destaque, mantinham e reforçavam uma tradição que tendia a ser percebida como inscrita na própria natureza de membros de linhagens de "guerreiros", a exemplo dos Marques de Souza, dos Carneiro da Fontoura, dos Corrêa da Câmara, dos Andrade Neves, dos Menna Barreto.

Entre as estratégias de reprodução adotadas por essas linhagens, sem dúvida é central o lugar ocupado pelas de caráter matrimonial, "parte das estratégias mais amplas de investimento social" (BOURDIEU, 1994, p. 6). Instrumento chave na manutenção e ampliação sobretudo dos capitais econômico e social, as alianças matrimoniais - que uniam descendentes de famílias tradicionais de proprietários e/ou de militares, ou ainda duplicavam laços de parentesco já existentes entre membros de um mesmo grupo familiar amplo - se destacam nessas frações dominantes ${ }^{15}$.

14. Conforme aponta Grijó (1998, p. 33-34), a condição de militar, entre os oficiais, poderia trazer em retribuição a serviços prestados a concessão de sesmarias, ao mesmo tempo em que a condição de estancieiro poderia também ser seguida de um posto de oficial nas milíciais e, depois de 1831, na Guarda Nacional. 0 título de coronel, primeiro das milícias organizadas e depois da Guarda Nacional, ou um título vinculado a uma posição no Exército que poderia mesmo ser honorífica, passou também a ser o designativo destes líderes político-guerreiros locais. Os coronéis, pois, reforçavam sua legitimidade frente ao domínio que exerciam sobre os seus clientes-peões e ampliavam-na na medida em que passavam a atuar no plano provincial. Pela patronagem exercida socialmente abaixo em relação aos seus peões e pela legitimidade político-militar que recebiam do Estado, tornavam-se mediadores por excelência entre estes dois planos. E era enquanto tais que se relacionavam com os demais coronéis e com as instâncias formais do poder». 15. É importante notar que tanto a endogamia quanto o casamento entre diferentes famílias de militares é traço que permanece no Exécito do Brasil. Como mostrou Barros (2018, p. 185) com respeito ao oficialato ativo nos anos 1960 e 1970, "a endogamia era comum entre militares por vários motivos, entre os quais a 'hereditariedade de vocação', as facilidades educacionais proporcionadas aos filhos de militares para ingressar na carreira etc." E "situações envolvendo o casamento de oficiais militares com as filhas de superiores ocorriam com grande frequência. Outro padrão observado foi o de oficiais casando-se com irmãs de seus pares profissionais”. Sobre as alianças entre linhagens de estancieiros no Rio Grande do Sul, consultar Piccin (2012, 2015). 
Obviamente, um dos principais dividendos obtidos pelo entrelaçamento de famílias com tradição militar, mas também com outras linhagens em posições homólogas, era o aumento na extensão das redes de relações à disposição do conjunto do grupo. Se como um todo essas alianças significavam acréscimo no montante total do capital de relações, incrementava em especial o portfólio de ligações dentro do domínio militar, em particular, do Exército. 0 padrão intenso de uniões endogâmicas e entre filhos de diferentes "famílias de militares", mantido ao longo do tempo, está na base do processo de construção de patrimônios sociais multidimensionais, em que se destaca um capital simbólico peculiar a essas estirpes de militares. Ao transmitirem com sucesso, ao longo de gerações, a “vocação”, isto é, o interesse e o investimento em posições de poder no Exército (e no espaço social mais amplo), constituíram trunfo social potente e de reconhecimento nunca somente restrito a um espaço profissional ${ }^{16}$.

\section{Os Menna Barreto: seis gerações de sol- dados}

\subsection{Dois livros sobre a estirpe}

Provavelmente o grupo familiar que forneceu maior quantidade de oficiais ao Exército brasileiro até o presente, os Menna Barreto encarnam um fenômeno impressionante de reprodução social de uma linhagem no seio de uma instituição associdada à estrutura administrativa de um país. As condições sociais de constituição da "família”, inseparáveis do processo de estruturação do Exército brasileiro - e também do próprio sistema de ocupação das terras mais ao sul da então colônia portuguesa -, tornam o estudo da trajetória do grupo um bom recurso para a apreensão dos mecanismos de formação e seleção da elite militar e de outros grupos dominantes. Ao se examinarem as origens da relação entre o grupo familiar amplo e o Exército, bem como a natureza dos trunfos e os tipos de estratégias empregados ao longo do tempo, amplia-se a possibilidade de entendimento dos elos entre a reprodução do grupo familiar e a da instituição militar, visualizando-se parte de suas variações e constantes ao longo de cerca de dois séculos ${ }^{17}$.

16. A atenção aqui dada à indissociabilidade entre diferentes domínios sociais - o político, o da "estância” e o militar - remete ao fenômeno de múltiplas (e indissociáveis) notabilidades, ligadas a configurações históricas marcadas pela multiposicionalidade dos agentes e pela multidimensionalidade nas fontes de créditos personificados, como indicam Grill \& Reis (2018) e Reis \& Grill (2017) ao tratarem em especial das elites políticas e intelectuais brasileiras.

17. Expediente semelhante é utilizado com proveito por Adriana Barreto de Souza em seus trabalhos sobre o Duque de Caxias e outros “vultos” do Exército (SOUZA, 2008, 2009, 2018). 
Até o final da década de 1960 os Menna Barreto contavam um total de 103 militares dentro da linhagem. Desses, 28 chegaram às graduações mais altas na hierarquia do Exército e muitos alcançaram outras patentes do oficialato superior (ver anexo). Referências ao nome Menna Barreto como sinônimo de família de militares, símbolo de "qualidades especiais" ligadas àquele domínio, são abundantes na literatura histórico-militar. Também são numerosas em documentação institucional variada, por exemplo, na forma de elogios, homenagens e considerações encontradas nas fés-de-ofício dos oficiais. Anos atrás, em conversa que tive com major responsável pelo setor de comunicação do Colégio Militar de Porto Alegre, a menção que fiz à família lhe entusiasmou. De pronto, chamou em voz alta, apenas pelo sobrenome, um jovem aluno que estava no pátio e veio até nós. Era um Menna Barreto. Perguntado pelo oficial sobre material da família, disse que "veria em casa" ou com algum parente.

A principal fonte de informação para esse estudo foram os dois volumes dedicados à "família”, escritos por um de seus membros. 0 autor é homônimo do "fundador” dos Menna Barreto" - todos de mesmo nome -, e ele próprio filho de um general, ou seja, de um oficial militar que foi para a reserva no posto de general. 0 primeiro livro se intitula Os Menna Barreto: seis gerações de soldados (1769-1950). Com mais de 500 páginas, foi publicado em 1950, quando o autor João de Deus Noronha Menna Barreto contava 48 anos de idade e ainda estava na ativa do Exército, com a patente de tenente-coronel. Esse dado sugere que, além da tarefa evidente de consa- gração social da "família" e de sua "particular estirpe”, o empreendimento servia ao mesmo tempo como recurso de afirmação no espaço institucional. Afınal, se tratava de um "trabalho" também consagrador do Exército nacional e com peso no currículo do oficial ${ }^{18}$.

Publicado vinte anos mais tarde, o segundo volume é uma continuação no levantamento das carreiras profissionais dos membros mais "ilustres" da "família", isto é, aqueles que chegaram a altas patentes militares. 0 autor já era, então, general de divisão reformado (aposentado). 0 livro de mais de 400 páginas se chama Ainda os Menna Barreto (1919-1969) e encerraria a

18. São frequentes as publicações de pesquisas de caráter "histórico" realizadas por oficiais superiores com frequência orientadas por projetos de enaltecimento e de homenagens ao Exército e a seus símbolos -, os quais lucram com a publicização de seus nomes dentro e, às vezes, também fora da instituição. Muitos desses "oficiais pesquisadores”, membros da Academia Militar de História (RJ), também integram outros institutos de pesquisa histórica, notadamente os Institutos Histórico e Geográfico regionais. Sobre a produção de material escrito e o trabalho de mediação cultural por agentes com interesses institucionais, consultar Seidl (2016, p. 101-104). 
tarefa de retraçar as "biografias", os "feitos" e as "glórias familiares" até a primeira geração posterior à do autor, no final da década de 1960. 0 fato de o autor ter incluído sua própria biografia na obra, como membro da quinta geração de militares, confere a uma parte do livro forte cunho autobiográfico e memorialístico. Em diversos momentos trata de situações nas quais afirma ter estado envolvido pessoalmente, fazendo de si próprio "testemunha insuspeita” e "narrador/historiador fiel”, como por exemplo na articulação do movimento que resultou na revolução de 1930.

Figura 1 - Parte da capa do livro, com brasão da família.

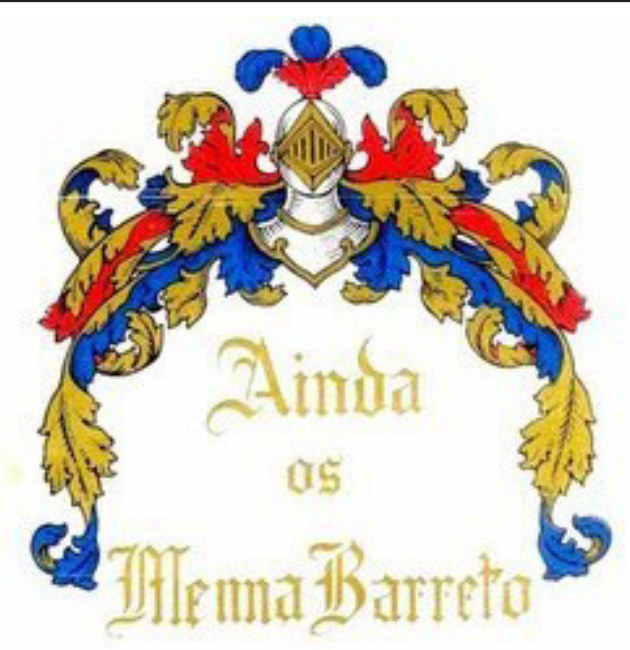

A produção desse tipo de obra por um descendente de linhagem tradicional segue lógica próxima à encontrada no material sobre famílias da antiga nobreza e da alta burguesia. Na França, Saint Martin (1980, 1992 e 1993) e Pinçon e Pinçon-Charlot (1997, 2000) mostram como a elaboração de materiais que reconstituem estrategicamente a "história" de "grandes famílias" (livros, memórias, genealogias, diários) - desde as gerações mais remotas até aquela que inclui o próprio autor, com o "resgate" de episódios, de pessoas e de outras famílias com os quais membros do grupo se relacionaram -, sugere que tais linhagens continuam a existir. E mais, que o "chefe atual do nome”, incumbido de perpetuá-las socialmente, cumpriu seu dever de "mantê-lo e honrá-lo". Funcionando como índice social de prestígio que remete à toda história familiar, que por sua vez acumula décadas e às vezes séculos de ligações com outras "grandes famílias", o "nome de família" permanece um dos principais trunfos a ser valorizado de modo constante por quem o carrega. Ao mesmo tempo, deve ser defendido "com honra" em casos de ataques ou outras vicissitudes que venha a sofrer, com risco de desvalorização.

Essas considerações são pertinentes para o caso em questão. Ao retraçar desde sua "fundação" as origens e a "evolução" da "família" - baseado em vasta documentação genealógica -, o militar-autor pretende também relacioná-las com a "evolução da história brasileira”, "que também é a do Exército". Para isso, destaca "fatos" e episódios "históricos" protagonizados por seus ascendentes. Considerando o contexto em que se desenrolaram suas biografias - em grande parte, oficiais comandantes com participação em guerras (Cisplatina, Uruguai, Paraguai), conflitos e movimentos político-militares, como as chamadas "revoluções (Farroupilha, Proclamação da República, Federalista, Tenentismo, Revolução de 1930) -, há um esforço de exaltação dessas "personalidades" que seriam portadoras de virtudes herdadas e postas a serviço do Exército, isto é, da "pátria”, como se vê na passagem abaixo:

Esse é o sentido alto do nosso trabalho, conquanto consiste em fazer conhecida a estirpe 
dos MENNA BARRETO, notadamente os militares, que haviam de destacar-se pelas suas atuações históricas, espadas sempre postas ao serviço da honra e da segurança do Brasil. (...) Impunha-se naturalmente para completar a empresa: enquadrar a vida dos MENNA BARRETO no tempo e no espaço. Destarte, pela devida definição do momento histórico em que atuaram os biografados, mais exatamente ressalta o seu merecimento, o significado duradouro de suas obras valerosas, conquanto nem sempre reconhecidas ou, às vezes tendenciosamente silenciadas (MENNA BARRETO, 1950: 11 e 21, maiúsculas no original).

\subsection{A "fundação" da "família" e as origens militares}

Como no caso de muitas "antigas famílias” do Rio Grande do Sul (FORTES, 1931), a "fundação" da "família” Menna Barreto remonta à conquista militar da região Sul e ao estabelecimento dos primeiros núcleos povoadores da província, atraídos pela distribuição de terras organizada pelo brigadeiro e administrador colonial José da Silva Paes, no século XVIII. Dentro do princípio prebendalista de distribuição de propriedades pela Coroa, recebiam mais terras os militares que apresentavam maior folha de serviços prestados. Entre eles estava o pai do "fundador" dos Menna Barreto, coronel de Dragões Francisco Barreto Pereira Pinto, português filho de um capitão-mor. Sua esposa era Francisca Veloso da Fontoura, brasileira de Minas Gerais, filha do português João Carneiro da Fontoura, que também tinha dois filhos oficiais dos Dragões ${ }^{19}$.
0 casal Carneiro da Fontoura, por sua vez, fizera parte dos primeiros colonizadores portugueses da Colônia do Sacramento, em 1737, indo após para o Forte de Rio Grande, e por fim para Rio Pardo, onde se instalou definitivamente. Tendo galgado alguns postos do oficialato, em 1762 Francisco Barreto Pereira Pinto foi nomeado Comandante do Regimento de Dragões em Rio Pardo, como tenente-coronel. Foi encarregado de conquistar e distribuir terras que iam sendo incorporadas à Coroa Portuguesa. Sua nomeação para assumir interinamente o governo da então Capitania do Rio Grande São Pedro, em 1763, dá pistas sobre o capital de prestígio e de relações que acumulara.

Francisco Barreto e Francisca Veloso tiveram doze filhos, entre eles o "fundador" da "estirpe", João de Deus Pereira Pinto. Ao se casar com Rita Bernardina Cortes de Figueiredo Menna, natural do Rio de Janeiro e filha de um tenente português, adotou o sobrenome Menna Barreto, dando origem à "família”. 0 único irmão homem de João de Deus foi Francisco Barreto Pereira Pinto Filho, que veio a ser tenente-coronel do Exército e desposou Eulália J. de Oliveira Roriz, filha do tenente Manuel Pereira Roriz, que fazia parte daquelas famílias agraciadas pela repartição inicial de propriedades fundiárias na região. Quase todas as dez irmãs de João de Deus se casaram com militares, "na maioria oficiais do Regimento (de Dragões) comandado pelo pai”, como é o caso de Maria Inocência, que se "casou com o capitão Miguel Pedroso Leite, ofıcial paulista, que muita glória adquiriu para o seu nome e que tam-

19. Os Dragões constituíam um dos tipos de tropa militar de maior prestígio durante o período colonial, com missões militares de defesa externa e de segurança interna. Foram extintas logo após a independência do País. 
bém deixou uma geração ilustre" (MENNA BARRETO, 1950, p. 29-30).

Nascido em Rio Pardo em 1769, onde seu pai servia como ofıcial, João de Deus veio a se instalar mais tarde em São Gabriel, município do qual "foi um dos fundadores" - organizando o $1^{\circ}$ Regimento de Cavalaria Miliciana destinado à guerra com o Uruguai. Em São Gabriel, era dono das "estâncias do Céu e do Batovi, doadas pelo Imperador" (MENNA BARRETO, 1950, p. 30). Note-se que o pai e o sobrinho de João de Deus, o futuro marechal do Exército Sebastião Francisco, já haviam sido concessionários das terras em forma de estâncias na futura São Gabriel, dentro da estratégia portuguesa de conquista e reconquista daqueles territórios junto aos espanhóis. João de Deus e seu primogênito Gaspar Francisco, também militar e futuro marechal, fizeram parte dos "povoadores” contemplados na "nova distribuição de terras feitas pelo governo, mais particularmente entre os militares que se haviam destacado na última campanha, aproveitando os campos deixados pelos espanhóis, considerados devolutos" (FIGUEIREDO, 1980, p. 77) ${ }^{20}$.

Às condições favoráveis dos Menna Barreto de acúmulo inicial de um patrimônio econômico importante se somou o estabelecimento de alianças matrimoniais com outros grupos familiares de características semelhantes, as quais tenderam a multiplicar o conjunto de recursos da linhagem. Foram predominantes por gerações os casamentos com descendentes de outras famílias de estancieiros, estancieiros-militares ou estancieiros-bacharéis, como demonstrou Piccin (2012) em trabalho sobre o patronato rural estancieiro do Rio Grande do Sul.

0 espaço limitado de possíveis para os descendentes desses grupos, pelo menos até as primeiras décadas do século XX, sem dúvida facilitava as tarefas de enquadramento e controle sobre seus destinos sociais. Afora seguir com a tradição no Exército sem abrir mão das posses herdadas, restavam como horizonte viável os cursos de direito e de medicina. Estas foram alternativas seguidas com maior frequência por membros das gerações nascidas no século XX, alguns deles já menos aquinhoados na distribuição de terras e de gado e para quem a carreira militar não ofereceria tanta segurança ou notabilidade $^{21}$. Como ocorria em outros grupos dominantes ligados às estâncias no Rio Grande do Sul (GRIJÓ, 1998; PICCIN, 2012), esses títulos escolares funcionavam sobretudo como recurso de legitimação para ocupação de cargos políticos e não propriamente para a realização de uma carreira centrada na profissão de médico, advogado ou engenheiro.

20. 0 estudo de Farinatti (2009) mostra que a construção de grandes patrimônios fundiários no espaço da fronteira incluía, além da doação de sesmarias, a ocupação simples, a compra e as usurpações. Em 1822, a concessão de sesmarias pela Coroa foi suspensa e, até 1850, a única forma de acesso à terra era a ocupação.

21. Sobre as estratégias de reconversão de membros das elites agrárias em ameaça de declínio no período, como a cafeeira em São Paulo e a açucareira em parte do Nordeste, consultar Miceli (1979) e Garcia Jr. (1993). Para um panorama mais amplo da morfologia do espaço do poder e das relações entre frações sociais e instrumentos de reprodução, consultar os trabalhos de Bordignon $(2015,2017)$ voltados às elites intelectuais e politicas. 


\subsection{A reprodução da "vocação": a espada de pai para filho}

0 exame dos itinerários sociais e profissionais dos Menna Barreto que chegaram à condição de elite do Exército, juntamente com o estudo mais amplo do grupo familiar, revela características similares às encontradas para o conjunto do alto oficialato nacional até em torno dos anos 1930. Há, contudo, particularidades que merecem destaque quanto ao sucesso peculiar logrado por esse grupo em sua relação com a instituição militar - e que o diferenciam em parte dos demais. Um primeiro aspecto diz respeito às condições iniciais de constituição do grupo familiar amplo, conforme mencionado, colocando seus primeiros membros em posição de acesso privilegiado a recursos fundamentais na época; por um lado, as terras distribuídas em larga escala pela Coroa; por outro, as relações com agentes em postos de poder na burocracia colonial e imperial. Conectado a isso está o envolvimento de membros do grupo, desde as primeiras gerações, com ocupações políticas em cargos de relevância, em parte uma decorrência da interconexão entre atividades político-administrativas e militares ao longo da colonização e de todo período imperial.

Para citar apenas os indivíduos nascidos no século XVIII, além do pai do "fundador" da "família”, Francisco Barreto Pereira Pinto, oficial militar encarregado de distribuição de terras na região sul e nomeado para assumir temporariamente o governo naquele território, o próprio João de Deus Menna Barreto (1769-1849) foi eleito VicePresidente da Junta Representativa do Governo na província, assumindo em 1822 a presidência e o cargo de Governador das
Armas (responsável provincial pelas forças militares). Já como marechal do Exército, em 1846 receberia de D. Pedro II o título de Visconde de São Gabriel. Da mesma forma, seu sobrinho, filho do tenente-coronel de Dragões Francisco Barreto Pereira Pinto Filho, foi nomeado Comandante das Armas em Pernambuco e em São Paulo (recusando ambas nomeações), e no Rio Grande, mais tarde assumindo a presidência da província de Minas Gerais, entre 1839 e 1840.

Mais pronunciadas nas primeiras gerações, as alianças matrimoniais estabelecidas pelos Menna Barreto permaneceram em seu conjunto voltadas essencialmente para a união com outros grupos ligados à alta hierarquia militar, inclusive parentes muito próximos, e também com descendentes de grandes proprietários de terras. Afora a intensidade de alianças que enlaçavam agentes social e geograficamente pouco distantes entre si, interessa ver a qualidade dessas uniões e os respectivos bens e lucros implicados, seguindo Desrosières (1978, p. 97), para quem “um casamento (...) é uma troca que coloca na balança espécies variadas de capital", sendo "a probabilidade de uma união tanto mais forte quanto mais ‘equilibrada' for a troca”.

Descontada a primeira geração e seus ascendentes, examinados anteriormente, pode-se resumir da seguinte forma o quadro de alianças matrimoniais dos Menna Barreto até em torno dos anos 1970:

i) Entre os dezoito descendentes que pertencem à segunda geração, duas netas casaram com oficiais militares e pelo menos quatro dos homens, todos oficiais, casaram com filhas de militares e/ou proprietários de terras;

ii) na terceira geração, oito netas casaram com oficiais; duas delas tiveram segundas núpcias, uma vindo a desposar um 
"doutor" e outra um desembargador; além dessas, mais três mulheres realizaram "bons casamentos”, incluídos enlaces com outro "doutor" e com um desembargador, e também com o filho de um Barão do Império; quanto aos homens, sete se uniram com esposas oriundas de famílias de militares;

iii) na quarta geração, seguindo tendência crescente, quatorze mulheres se enlaçaram com oficiais militares e doze com "doutores", ao passo que também doze dos homens (sete militares) concretizaram matrimônios que seguiram o mesmo padrão anterior, com destaque a um acréscimo significativo nos entrelaçamentos dentro do próprio grupo familiar amplo; iv) com respeito à quinta geração, nove mulheres casaram com oficiais, treze com "doutores" e uma com um cônsul; para esta geração e a seguinte as informações sobre os casamentos dos descendentes homens são bastante vagas e incompletas. Pôde-se registrar, no entanto, o enlace com barões e viscondes;

v) por fim, para a sexta e última geração examinada se registra o casamento de seis tetranetas com oficiais militares e de três com "doutores". Um dos homens desta geração se casou com uma "Noronha”, família de longa tradição na Marinha, em duas gerações consecutivas.

Quadro 1 - Síntese de casamentos de mulheres Menna Barreto com militares e "doutores" e descendentes homens com o título de "doutor"

\begin{tabular}{llllll}
\hline Profissão/Geração & 2a geração & 3a geração & $4^{\text {a }}$ geração & 5a geração & 6a geração \\
Casadas com militares & 02 & 08 & 14 & 09 & 06 \\
Casadas com “doutores” & 00 & 05 & 12 & $14^{22}$ & 03 \\
Homens “doutores” & 00 & 00 & 08 & 09 & 03 \\
\hline
\end{tabular}

Fonte: Menna Barreto (1950, 1970).

Quadro 2 - Síntese dos casamentos de homens Menna Barreto em cinco gerações

\begin{tabular}{|c|c|c|c|c|}
\hline $2^{\mathrm{a}}$ & $3^{a}$ & $4^{a}$ & $5^{\mathrm{a}}$ & $6^{\mathrm{a}}$ \\
\hline $\begin{array}{l}4 \text { casamentos } \\
\text { com filhas de mi- } \\
\text { litares e proprie- } \\
\text { tários fundiários }\end{array}$ & $\begin{array}{l}7 \text { casamentos } \\
\text { com filhas de } \\
\text { oficiais militares }\end{array}$ & $\begin{array}{l}12 \text { (7 militares) ca- } \\
\text { samentos com fi- } \\
\text { lhas de oficiais mi- } \\
\text { litares e de pro- } \\
\text { prietários; inten- } \\
\text { sificação de entre- } \\
\text { laçamentos dentro } \\
\text { do próprio grupo } \\
\text { familiar }\end{array}$ & $\begin{array}{l}\text { casamentos com } \\
\text { descendentes } \\
\text { de famílias pos- } \\
\text { suindo títulos } \\
\text { nobiliárquicos } \\
\text { (barões e vis- } \\
\text { condes) }\end{array}$ & $\begin{array}{l}\text { entrelaçamento } \\
\text { com “família” No- } \\
\text { ronha, de longa } \\
\text { tradição na Mari- } \\
\text { nha nacional }\end{array}$ \\
\hline
\end{tabular}

Fonte: Menna Barreto (1950, 1970).

22. Inclui o casamento com um Cônsul. 
Ao lado da manutenção de casamentos com grupos ligados às Forças Armadas, chama atenção o predomínio de enlaces com membros de famílias em posições dominantes, como estancieiros, bacharéis e médicos. A diversificação dos destinos sociais dos Menna Barreto também aparece nos diplomas obtidos pelos homens, em especial a partir da quarta geração (seis bisnetos foram bacharéis em Direito e dois foram médicos). Destaque-se que um ramo expressivo da linhagem se manteve ligado a atividades estancieiras e charqueadoras na região de origem do grupo, São Gabriel, conhecida como terra dos marechais ${ }^{23}$, onde os Menna Barreto gozam de alta reputação até o presente ${ }^{24}$.

\subsection{A espada a serviço da Pátria: a carrei- ra, a política e a história}

Como visto, as relações dos Menna Barreto com as forças armadas (de Portugal e da Coroa brasileira) e com atividades político-militares de ocupação e defesa do território remontam à própria "fundação" da família no extremo sul da Colônia. Foram determinantes na constituição desse grupo familiar cujo itinerário é marcado pelo uso de recursos derivados daquelas mesmas relações: extensas propriedades de terras, posições de poder no Exército, ocupação de altos cargos político-administrativos, vínculos com agentes das esferas político-burocráticas.

Tomados em conjunto, os itinerários dos principais membros da família que ascenderam ao alto oficialato mostram continuidade no padrão de relacionamento com a carreira militar. Isto é, na natureza dos recursos mobilizados e nos modos como foram empregados ao longo das sucessivas posições que ocupavam no espaço social e no interior do espaço militar. Entre esses recursos se destaca o envolvimento direto com o universo da "política" e o entretenimento de relações próximas com agentes dotados de alto capital político, com os quais eram trocados outros recursos valiosos, em ambos os domínios. Por exemplo, a troca de lealdade política do militar por influências ou indicações para nomeações em cargos importantes e promoções hierárquicas ${ }^{25}$.

No entanto, o que mais interessa nesse ponto são as formas como se desenvolveram e se mantiveram as relações dos oficiais Menna Barreto com o universo da política. Essas relações favoreceram os futuros generais da família no acesso a benefícios e a posições importantes na esfera militar e política, base de uma consagração social que não se prenderia apenas ao número muito elevado de militares na família, mas a uma projeção mais ampla no espaço social.

23. Pelo menos três marechais nasceram em São Gabriel: João Propício Menna Barreto (1808-1867), Barão de São Gabriel, Hermes da Fonseca (1855-1923), presidente da República e João Batista Mascarenhas de Morais (1883-1968), Comandante da Força Expedicionária Brasileira na 2a Guerra Mundial.

24. Com base em extenso trabalho de campo, Piccin (2012, p. 219-220) afirma que (...) "trata-se de uma família considerada por outros estancieiros como a mais importante do município, devido ao poder simbólico que carrega. Uma das mais aristocráticas dentre as demais, um casamento entre os primos na segunda geração foi considerado como a continuidade do poder simbólico na linhagem, cuja distinção se dava por um conjunto de símbolos que ostentavam a história da família, dentre os quais um pequeno museu familiar e, até o final da década de 1980, leões em sua casa próxima da cidade do município”.

25. Para uma demonstração detalhada sobre o funcionamento prático dessas relações personalizadas, ver Seidl (1999, espec. p. 74-114, 2008, 2011). 
Os itinerários de dois generais - tio-avô e sobrinho-neto - tratados nesta seção auxiliam nessa demonstração. 0 primeiro foi deputado constituinte em 1891 e Ministro da Guerra; o segundo integrou a Junta Governativa que assumiu o poder no País, provisoriamente, após o golpe de 1930.

Como apontado acima, um dos aspectos reveladores da "grandeza" e da "importância" atribuídos à "estirpe" pela narrativa sobre os Menna Barreto seria a constante participação da família nos "principais episódios da história brasileira” - desde a "fundação do Rio Grande" até o golpe de 1964. Nas estratégias de apresentação e consagração da família esse elemento aparece de fato como trunfo fundamental a ser celebrado e perpetuado: tanto como forma de reconhecimento social mais amplo e, em particular no âmbito militar, quanto de reconhecimento pelos próprios descendentes, para que "saibam o lugar que devem ocupar" na sociedade e, assim, conheçam as condições para reproduzir à altura o grupo familiar ao qual pertencem.

É possivel afirmar que entre a metade do século XIX e a Primeira República houve uma relativa intensificação dos vínculos entre os militares da família e a esfera da "política”, o que se expressou na composição de carreiras que atingiram relevo em nível nacional e favoreceu, afınal, uma imagem social da "família" associada a posições privilegiadas na "elaboração dos destinos da nação”. Boa parte do sucesso dos militares Menna Barreto se deveu a uma herança político-militar acumulada há muito tempo e legada por seus ancestrais "políticos/militares”, herança da qual souberam extrair lucros e rentabilizar nos espaços em que se deslocavam. Assim, quando da organização e fortalecimento do Partido Republicano no Rio Grande do Sul em torno da década de 1880, vários oficiais da família, ainda com patentes de nível médio, aderiram com intensidade ao partido - alguns deles se tornando propagandistas ativos.

Esse é o caso do futuro marechal Antônio Adolfo da Fontoura Menna Barreto (18461923) - filho de outro marechal - que, quando tenente, escolhera a política como "novo campo de ação" e se alistara, inicialmente, nas fileiras do Partido Conservador na fronteira da província, vindo depois a deixá-lo face a seu "desapontamento" e "insatisfação" com a liderança do partido. Sua saída do Partido Conservador e imediata adesão ao Republicano coincidem com a perda de força do primeiro frente ao domínio do Partido Liberal de Silveira Martins e a rápida ascensão do segundo em nível regional e nacional, com atração de grande número de oficiais do Exército. Transferido para o Rio de Janeiro, Antônio Adolfo assumiu papel destacado, ao lado de seu parente Frederico Solon Ribeiro, nas ligações entre republicanos civis e militares, contando com o auxílio de mais três primos oficiais Menna Barreto ${ }^{26}$.

Uma vez proclamada a República, poderia enfım o oficial dar continuidade a uma ascensão hierárquica "condizente com seu nome”, pois até então Menna Barreto, já aos 43 anos de idade e sem nenhum investimento escolar, não havia ultrapassado a patente subalterna de capitão. Como aponta seu "biógrafo", "foi tal a perseguição que lhe movia a aristocracia reinante, que

26. Entre eles se encontrava o então capitão e futuro general Manoel Joaquim Menna Barreto Godolfim, também filiado ao Partido Republicano e muito próximo de estrelas de primeira grandeza da política republicana gaúcha, como Júlio de Castilhos, Borges de Medeiros e Pinheiro Machado. 
só com a proclamação da república conseguiria os galões de major, (...) por serviços relevantes"; e ainda, "como recompensa a seus grandes serviços à nobre causa republicana, obteve, sem demora, a 17 de março desse mesmo ano (1890), o posto de tenente-coronel, e logo o comando do Regimento de Cavalaria Policial do Distrito Federal" (MENNA BARRET0, 1950, p. 325, grifos meus).

Fruto de um engajamento político explícito e bem-sucedido, o impulso dado à "carreira" (subindo duas patentes em questão de meses!) e a notoriedade então obtida por Antônio Adolfo na capital do País lhe permitiram investir com maior intensidade na "política", transformando-se em aliado intenso do Governador do Rio Grande do Sul, Júlio de Castilhos. Ao voltar para o Rio Grande do Sul, em 1890, elegeu-se deputado para a Assembleia Constituinte Nacional. Definia-se "como um dos mais devotados amigos de Deodoro" (MENNA BARRETO, 1950, p. 292), "amizade" esta nascida à época do movimento conspirativo contra a monarquia.

Além disso, esse “engajamento" também lhe traria um bloqueio momentâneo na carreira. Por sua participação na "Carta dos treze generais" do Exército e da Armada documento que incitava Floriano Peixoto a proceder às eleições para a Presidência -, foi preso, reformado e desterrado para o Acre. Pouco depois, no entanto, retornou às atividades no Congresso e foi no- meado Comandante da Reserva da Brigada Militar ${ }^{27}$ e de todas as forças civis no Rio Grande do Sul, posto de competência política atrelada ao Governador, para combater na Revolução Federalista (1893-1895). Terminada a guerra, recebeu honras de general de brigada "pelos importantes serviços prestado à República, e pelos atos de bravura praticados mais de uma vez em defesa da República no Estado do Rio Grande do Sul” (MENNA BARRETO, 1950, p. 296), revertendo à primeira classe do Exército um ano depois.

Por fazer "franca oposição" ao Governador do Paraná, onde servia, Menna Barreto foi novamente preso por três meses e solicitou a reforma em vista das "perseguições de que o Governo o fazia alvo". Ainda mais uma vez teria sua reversão à ativa do Exército decretada em 1907 pelo Congresso, e no posto de general. Antes, porém, de pedir a reforma definitiva e pôr fim a uma "carreira" fortemente marcada por disputas pessoais decorrentes de tomadas de posição política, Antônio Adolfo ascenderia ao mais alto cargo na hierarquia militar, o de Ministro do Exército ${ }^{28}$, "honrando" assim a "tradição" à qual pertencia.

Se o itinerário de Antônio Adolfo foi pautado por intensa atividade política ao longo de toda a vida de oficial e da qual extraiu recursos centrais a seu êxito, de certa forma compensando a escassez de outros trunfos, como "competência técnica" e "cultura geral”, o de seu sobrinho-neto

27. Força policial provincial com características militares, criada em 1837 no Rio Grande do Sul.

28. A esse respeito, escreveu o marechal gaúcho Setembrino de Carvalho em suas memórias que a "amizade pessoal de Menna Barreto com o marechal Hermes e o "general" Pinheiro Machado, dos quais era "depositário de inteira confiança", tivera peso decisivo em sua nomeação. "Dar-lhe uma posição de realce em seu governo [Hermes], deveria ser mesmo para o Marechal um tributo de gratidão, pois certo fora ele um dos mais ardorosos paladinos de sua ascenção (sic) à mais alta magistratura da República" (CARVALHO, 1950, p. 91). 
João de Deus Menna Barreto (1874-1933) se diferencia bastante. Os princípios gerais, no entanto, foram mantidos. Isto é, ao passo que Antônio Adolfo, desde muito cedo, se dedicara ao acúmulo e manutenção de um capital político, João de Deus manteve uma relação mais distanciada e eufemizada frente ao domínio político. Em contrapartida, o "atraso" na carreira do tio e a "rapidez" com que avançou nos primeiros postos proporcionaram uma aproximação temporal em seus itinerários profıssionais, o que permitiu a João de Deus se beneficiar de muitos dos trunfos acumulados pelo parente dezoito anos mais velho.

Ao contrário de Antônio Adolfo, João de Deus, homônimo do "fundador" dos Menna Barreto, cumprira a exigência formal em vigor de obter formação escolar para progredir na carreira. Iniciou estudos em Porto Alegre e concluiu no Rio de Janeiro, de onde saiu habilitado com o curso das três armas combatentes (artilharia, infantaria e cavalaria). Antes, porém, havia deixado temporariamente a Escola de Porto Alegre para servir na Revolução Federalista, em 1893. Naquela ocasião foi nomeado, com apenas 19 anos de idade e ainda estudante, Assistente do Ajudante General da Divisão do Norte ${ }^{29}$, a qual tinha em seu comando o senador Pinheiro Machado. Após um início de carreira bastante lento - aos 36 anos não havia ultrapassado o posto intermediário de capitão -, a "oportunidade" de servir junto a seu tio general, recentemente nomeado Comandante da $1^{\text {a }}$ Brigada Estratégica no
Rio de Janeiro, propiciou a João de Deus condições para galgar com velocidade posições importantes na hierarquia do Exército.

Assim, a ascensão e o destaque desfrutados pelo tio também impactaram a carreira do sobrinho. Logo após o serviço prestado junto a seu parente, João de Deus recebeu promoção para o posto de major, “por merecimento". E ainda acompanhou o tio à mais alta esfera militar, o Ministério da Guerra, onde trabalhou como Adjunto do Gabinete do Ministro. Antes de se demitir da pasta da Guerra, Antônio Adolfo nomeou o sobrinho como adjunto de professor de física e química da Escola Militar de Porto Alegre, cargo que manteve por pouco tempo, pois, se tratando de uma nomeação pessoal, o novo Ministro que o substituiu tratou de exonerar "alguns professores" assim que assumiu as funções.

A partir desse avanço na carreira o futuro general começaria a reunir os principais recursos para a ascensão. Tendo esperado vinte anos entre a patente de alferes (segundo-tenente) e a de capitão - sem dúvida, resultado em parte das reformas regulamentares que passaram a inibir o avanço precoce na hierarquia - para alcançar o generalato não lhe faltariam mais do que onze anos. Recebeu sua promoção quando contava apenas 47 anos de idade, um dos mais jovens de todo o Exército, enquanto a média de idade para o posto no período era de 54 anos.

A distância relativa assumida frente à "política” e também sua suposta incompati-

29. Esse expediente clássico de favoritismo e de proteção que aproxima indivíduos a autoridades e a espaços de poder, com frequência endereçado a indivíduos mais jovens em início de carreira, funciona como mola propulsora importante ao inseri-los em redes de relações privilegiadas e expô-los, precocemente, a uma série de códigos e práticas próprios a instâncias de decisão. Usual em muitos espaços institucionais, receber a proteção de algum superior hierárquico no Exército costuma ser denominado "ser peixe" de fulano. Sobre o favoritismo em diferentes instituições formais, ver Wolf (1980); no próprio Exército, ver Seidl (2008); na Igreja Católica, consultar Seidl (2003, esp. p. 272-280) e Miceli (2009). 
bilidade com o serviço do Exército, até então alegados por Menna Barreto, sofreriam alterações a partir da entrada na alta esfera do oficialato. Se por um lado continuou a afirmar estrategicamente um "total desinteresse" pelas “questões políticas”, base do "profıssionalismo militar" que sustentava, por outro não pôde deixar de jogar o jogo segundo as regras. À diferença, por exemplo, das posições do conterrâneo e figura de visibilidade Bertoldo Klinger ${ }^{30}$ - defensor de um "intervencionismo militarista", "moderador", e a quem esteve muito ligado nos últimos anos de seu serviço na ativa -, à medida que se aproximou das instâncias militares mais dependentes da lógica política, João de Deus passou a justificar o envolvimento com a "política" tratando-o como algo "extraordinário", "temporário" e "imprescindivel". Sem deixar de defender o "afastamento do Exército das correntes políticas”, o oficial não negava a possibilidade de o militar vir a colaborar com seu serviço na administração civil sem ter de deixar a instituição (MENNA BARRETO, 1950).

Após promoção ao generalato em 1921, João de Deus exercitaria com intensidade as habilidades políticas exigidas de um alto oficial. Logo em 1922, esteve à frente no combate aos levantes dos "tenentes" no Rio de Janeiro e em Mato Grosso. Em 1924, chefiou expedição para combater movimento idêntico no Amazonas, onde ofıciais haviam deposto o governo. Registre-se que naquela ocasião dois de seus filhos e também um primo serviram como oficiais de seu Estado-Maior! Segundo narra o biógrafo da família e filho do próprio João de Deus, as lideranças políticas teriam convidado o general a ser candidato ao Governo
Estadual, cargo que ele havia ocupado momentaneamente como interventor. Menna Barreto teria negado de pronto, dizendo-se "alheio por completo às competições políticas" e não desejando "afastar-se de seus deveres profissionais" (MENNA BARRETO, 1950, p. 452). Promovido, sem demora, a General de Divisão e nomeado Comandante da $1^{\text {a }}$ Região Militar pelo Presidente Artur Bernardes, em 1926 elegeu-se presidente do Clube Militar, onde foi muito ativo em suas duas gestões. Seria nos anos seguintes, no entanto, que chegaria ao ápice de sua carreira como oficial do Exército, ao participar do movimento militar que sustentou a deposição do presidente Washington Luís e garantiu a ascensão de Getúlio Vargas ao poder do País.

Novamente de acordo com o biógrafo e "testemunha participante" de grande parte dos acontecimentos, foi depois de procurado pelo então coronel Bertoldo Klinger - chefe de seu próprio Estado-Maior -, em "nome de um grupo de jovens oficiais do Exército", que seu pai João de Deus teria aderido aos propósitos de intervenção militar na "grave questão política que se colocava à nação". "Predisposto por índole" e não lhe sendo possível "subtrair-se à responsabilidade histórica dos MENNA BARRETO (p. 461, grifos meus, maiúsculas no original), assumiu a chefia do movimento que desembocou na criação de uma Junta Provisória de Governo. Além de Menna Barreto, também faziam parte da junta que governou o País até a posse de Vargas em novembro de 1931 o general Tasso Fragoso e o ContraAlmirante Isaías de Noronha.

Dissolvida a Junta Governativa, Menna Barreto teria em seguida outra participa- 
ção direta em atividades civis. A convite de Vargas, não "pôde recusar" a tarefa de assumir a Interventoria do Estado do Rio de Janeiro em 1931. Para isso, teria que ter "rompido com suas convicções" de que "o soldado não deve afastar-se da sua posição". Assim, antes de finalizar seu "destino de servidor da pátria" como Ministro do Supremo Tribunal Militar, João de Deus se manteve como Interventor do Estado politicamente mais importante do País à época até o final de outubro de 1931.

\section{Considerações finais}

Procurei neste artigo explicitar as condições históricas e os mecanismos de constituição de parte das frações dominantes brasileiras notabilizadas pelo vínculo com o "serviço" ao Exército e ao Estado. Centrado no caso de um único grupo familiar, os Menna Barreto, o estudo deu atenção especial às estratégias de reprodução e de carreira desse grupo que logrou manter, por muitas gerações, posição de destaque no espaço militar e do poder.

Longe de representar fenômeno isolado, no entanto, os Menna Barreto são apenas exemplo extremo da mecânica de formação não somente do espaço estatal, e em particular do Exército, mas do espaço social brasileiro de modo amplo. A dependência administrativa e política estrutural do Estado (português e depois brasileiro) frente aos serviços privados, fornecidos por grupos também em situação de dependência de prebendas variadas, emoldura quadro bastante conhecido pela literatura nacional e internacional sobre configurações patrimonialistas e protoburocráticas.

As peculiaridades do extremo sul do Brasil - região de fronteiras fortemente disputadas, de presença militar precoce e intensa - são, sem dúvida, ingrediente importante na constituição do fenômeno de grupos familiares especializados em atividades militares. Ator chave no esquema de administração imperial ao longo do século XIX, o militar-estancieiro reuniria recursos variados e valorizados para sua afirmação: terras, escravos, gado, reconhecimento do Estado, reputação, relações. 0 exercício de atividades militares e políticas em nome do Estado, com a contrapartida de recebimento de honrarias, títulos de nobreza e altas patentes do Exército, representaria ativo precioso na composição de patrimômio social transmissível a seus descendentes.

Como sabido, a baixa institucionalização do Exército (e do Estado como um todo) durante o Império significou a formação de um alto oficialato recrutado entre frações sociais dominantes, para as quais a carreira militar assumia, antes de mais nada, o sentido de acesso aos espaços de poder, com a necessária inserção em redes e a inscrição em facções políticas. As exigências de caráter considerado meritocrático, como a preparação em escolas ou academias, a aprovação em cursos e a adesão a valores de disciplina e hierarquia - critérios assumidos como essenciais nos moldes contemporâneos -, eram, de fato, questões muito mais debatidas do que objetivas na realidade do Exército até pelo menos o final do Império.

Como evidenciado, o acesso privilegiado à estrutura de benefícios ofertada pelo Estado - entre eles, postos de alto comando no Exército - foi peça mestra nas condições de produção e de reprodução social das elites no período. Na configuração aqui examinada em particular, as condições favoráveis de utilização da instituição militar por certos grupos familiares explicam o sucesso na transmissão de patrimônios 
sociais erigidos, em larga medida, em associação com serviços militares e político-administrativos prestados por membros notabilizados do grupo. 0 predomínio de critérios adscritivos, a valorização de vínculos pessoalizados e de lealdades políticas nas engrenagens de regulação do Exército, enquadravam, desse modo, o horizonte de investimentos para muitos membros desses grupos ao longo de gerações.

0 forte entrelaçamento de famílias de tradição no Exército entre si, e com outras em posição social homóloga, ressalta o cuidado na gestão dos destinos dos descendentes, cujo resultado tendia ao incremento de patrimônios econômicos e de importante portfólio de relações sociais e institucionais. Por meio de intensas alianças via matrimônio de filhos e filhas com membros de outras linhagens, e dentro da própria família extensa, a cada geração multiplicava-se a parentela dentro do Exército e de outras esferas de poder.

Frente à impossibilidade de transmissão direta do posto de oficial a um parente, as manobras de proteção, favoritismo e privilégio, entre outros expedientes com efeitos decisivos na instituição, se somavam à transmissão mais evidente de um capital simbólico colado a um nome de tradição no Exército. No caso dos Menna Barreto, uma longa lista de nomes remontando a gerações, com folhas corridas recheadas de feitos históricos e condecorações, os mais variados: heróis de guerra, marechais, generais, barão, visconde, presidente de província, interventor provincial, deputados, ministro da Guerra, membro de junta governativa do País.

A imposição gradativa de critérios escolares mais rígidos para ascensão ao oficialato, com o relativo fechamento da profıssão e defınição de uma carreira militar em moldes modernos, sem dúvida alterou a relação da instituição com os grupos dominantes. Menos prestigiada social e politicamente, com maiores exigências escolares, de treinamento e de renúncias pessoais (como o deslocamento constante pelo País), a profıssão militar viria a se tornar mais atraente a frações sociais intermediárias, mais dependentes do sistema escolar e dispostas a investimentos pessoais intensos.

A orientação de parte dos Menna Barreto, a partir do início do século XX, para profissões como direito, medicina e engenharia - em muitos casos associada a atividades pecuárias - sinaliza estratégia mais segura de rentabilização do patrimônio familiar, forte em reconhecimento social e político sobretudo em partes do Rio Grande do Sul. De fato, a análise dos destinos sociais e profissionais de gerações mais recentes, e de diferentes ramos do grupo, seria de interesse à compreensão de um quadro bastante amplo em torno das transformações do Estado, do Exército e do mundo da estância.

\section{Referências}

BARBOSA, F. D. História do Rio Grande do Sul. Porto Alegre: EST, 1983.

BARROS, A. S. C. Parentesco entre membros das Forças Armadas brasileiras. In: CASTR0, C. (Org.). A família militar no Brasil: transformações e permanências. Rio de Janeiro: FGV, 2018.

BENTO, C. M. História da 3a Região Militar (18071889/1889-1953). 2 v. Porto Alegre, 1994.

BORDIGNON, R. R. As faculdades de direito e o recrutamento de professores de ensino superior na Primeira República. Sociedade e Estado, v. 32, p. 749-770, 2017.

Elites políticas e intelectuais: condições de diversificação e estratégias de carreira (1870-1920). 2015. 410 f. Tese (Doutorado em 
Ciência Política) -, Programa de Pós-Graduação em Ciência Política, Universidade Federal do Rio Grande do Sul-UFRGS, Porto Alegre, 2015.

BOURDIEU, P. Espíritos de Estado: gênese e estrutura do campo burocrático. Apêndice: 0 espírito de família. In: BOURDIEU, P. Razões práticas: sobre a teoria da ação. 6. ed. Campinas: Papirus, 1996, p. 124-135.

Sobre o Estado. São Paulo: Companhia das Letras, 2014.

Stratégies de reproduction et modes de domination. Actes de la Recherche en Sciences Sociales, (105), déc., 1994, p. 3-12.

CARDOSO, F. H. Rio Grande do Sul e Santa Catarina. In: HOLANDA, S. B. (Org.). História Geral da Civilização Brasileira. O Brasil Monárquico. Tomo II. 2. ed. São Paulo: Difusão Europeia do Livro, 1967, p. 473-505.

CARVALHO, J. M. A construção da ordem: a elite política imperial; Teatro de Sombras: a política imperial. Rio de Janeiro: Editora da UFRJ/RelumeDumará, 2a edição revisada, 1996.

CARVALHO, S. Memórias: dados para a história do Brasil. Rio de Janeiro: 0 Cruzeiro, 1950.

CASTRO, C. A invenção do Exército brasileiro. Rio de Janeiro: Jorge Zahar, 2002.

A origem social dos militares. Novos Estudos - Cebrap, v. 37, p. 225-231, 1993.

0 espírito militar: um estudo de antropologia social na Academia Militar das Agulhas Negras. Rio de Janeiro: Jorge Zahar, 1990.

Os militares e a República: um estudo sobre cultura e ação política. Rio de Janeiro: Jorge Zahar, 1995.

DESROSIÈRES, A. Marché matrimonial et structures des classes sociales. Actes de la Recherche en Sciences Sociales, (20-21), p. 97-107, 1978.

FARINATTI, L. A. Apropriação da terra e a formação de grandes patrimônios fundiários na fronteira sul do Brasil, através dos inventários post mortem
(1800-1860). Trabajos y comunicaciones. Memória Acadêmica, v. 35, p. 149-171, 2009.

FÉLIX, L. O. Coronelismo, borgismo e cooptação política. Porto Alegre: Mercado Aberto, 1987.

FIGUEIRED0, O. S. São Gabriel desde o princípio. Santa Maria: Pallotti, 1980.

FORTES, J. B. Troncos seculares: o povoamento do Rio Grande do Sul. Rio de Janeiro, s.n., 1931.

GARCIA, G. B. 0 domínio da terra: conflitos e estrutura agrária na campanha Riograndense oitocentista. 2005. Dissertação. 195 f. (Mestrado em História) - Programa de Pós-Graduação em História, Universidade Federal do Rio Grande do Sul-UFRGS, Porto Alegre, 2005.

GARCIA JUNIOR, A. Reconversion des élites agraires: du pouvoir local au pouvoir national. Études Rurales, Paris, n. 131-132, 1993.

GRIJÓ, L. A. Origens sociais, estratégias de ascensão e recursos dos componentes da chamada “Geração de 1907”. 1998. Dissertação (Mestrado em Ciência Política) - Programa de Pós-Graduação em Ciência Política, Universidade Federal do Rio Grande do Sul-UFRGS, Porto Alegre, 1998.

GRILL, I. G. "Família", direito e política no Rio Grande do Sul: os usos do parentesco e dos títulos escolares no exercício do métier. Tomo, v. 10, p. 85-111, 2007.

"Heranças políticas" no Rio Grande do Sul. São Luís: Edufma, 2008.

GRILL, I. G.; REIS, E. T dos. Dos campos aos domínios das "elites" no Brasil. Tomo, p. 163-210, 2018.

; REIS, E. T. Elites parlamentares e a dupla arte de representar: intersecções entre política e cultura no Brasil. Rio de Janeiro: Editora FGV, 2016.

LEWIN, L. Política e parentela na Paraíba: um estudo de caso da oligarquia de base familiar. Rio de Janeiro: Record, 1993.

LOVE, J L. O regionalismo gaúcho e as origens da Revolução de 30. São Paulo: Perspectiva, 1975. 
McCANN, F. Soldados da Pátria: história do Exército brasileiro (1889-1937). São Paulo: Companhia das Letras, 2007.

MARTINS, M. de S. N. Entre a cruz e o capital: as corporações de ofícios no Rio de Janeiro após a chegada da família real (1808-1824). Rio de Janeiro: Garamond, 2008.

MENNA BARRETO, J. D. N. Os Menna Barreto: seis gerações de soldados. Rio de Janeiro: Laemmert, 1950.

Ainda os Menna Barreto (1919-1969).

Rio de Janeiro: Lammert, 1970.

MICELI, S. A elite eclesiástica brasileira. 2. ed. São Paulo: Companhia das Letras, 2009.

. Intelectuais e classe dirigente no Brasil (1920-1945). São Paulo: Difel, 1979.

NEUMANN, E. S. A fronteira tripartida: a formação do continente do Rio Grande - Século XVIII. In: GRIJÓ, L. A. et al. (Orgs). Capitulos de história do Rio Grande do Sul. Porto Alegre: UFRGS, 2004, p. 25-46.

OSÓRIO, H. Apropriação da terra no Rio Grande de São Pedro e a formação do espaço platino. 1990. Dissertação (Mestrado em História) Programa de Pós-Graduação em História, Porto Alegre, Universidade Federal do Rio Grande do Sul-UFRGS, Porto Alegre, 1990.

PICCIN, M. B. Acesso a posições de poder pela elite estancieira gaúcha: trajetórias sociais e investimentos escolares. Tempo Social, São Paulo, v. 27, n. 2, p. 305-328, 2015 .

Os senhores da terra e da guerra no Rio Grande do Sul: um estudo sobre as práticas de reprodução social do patronato rural estancieiro. 2012. 458 f. Tese (Doutorado em Ciências Sociais) - Programa de Pós-Graduação em em Ciências Sociais, Universidades Estadual de CampinasUnicamp, Campinas, 2012.

PINÇON, M. \& PINÇON-CHARLOT, M. Sociologie de la bourgeoisie. Paris: La Découverte, 2000.

Voyage en grande bourgeoisie: journal d'enquête. Paris: PUF, 1997.
REICHEL, H. J. Fronteiras no espaço platino. In: BOEIRA, N.; GOLIN, T. (Orgs.). Colônia. v. 1. Passo Fundo: Méritos, 2006, p. 43-64.

REIS, E. T.; GRILL, I. G. Estudos de elites políticas e as bases das multinotabilidades no Brasil. Tempo Social, 29(3), p. 137-159, 2017.

SAINT MARTIN, M. A nobreza em França: a tradição como crença. Revista Brasileira de Ciências Sociais, 20 (7), p. 148-161, out./1992.

L'espace de la noblesse. Paris: Métailié, 1993.

Une grande famille. Actes de la Recherche en Sciences Sociales, (31), p. 4-21, jan., 1980.

SCHULZ, J. O Exército e o Império. In: HOLLANDA, S. B.; CAMPOS, P. M. (Orgs.). História Geral da Civilização Brasileira: O Brasil Monárquico, Tomo IV, v. 2. São Paulo: Difel, 1977, p. 235-258.

0 Exército na política: origens da intervenção militar, 1850-1894. São Paulo: Edusp, 1994.

SEIDL, E. A elite eclesiástica do Rio Grande do Sul. 2003. 461 f. Tese (Doutorado em Ciência Política) - Programa de Pós-Graduação em Ciência Política, Universidade Federal do Rio Grande do Sul-UFRGS, Porto Alegre, 2003.

A espada como "vocação": padrões de recrutamento e de seleção das elites do Exército no Rio Grande do Sul (1850-1930). 1999. Dissertação (Mestrado em Ciência Política) - Programa de Pós-Graduação em Ciência Política, Universidade Federal do Rio Grande do Sul-UFRGS, Porto Alegre, 1999.

Elites e instituições: pistas para investigação. In: GRILL, I. G.; REIS, E. T. (Orgs.). Estudos sobre elites políticas e culturais: reflexões e aplicações não canônicas. São Luís: Edufma, 2016, p. 97-125.

Condicionantes sociais na composição do alto oficialato militar brasileiro (1850-1930). In: HEINZ, F. M. (Org.). História social de elites. v. 1, p. 11-27, São Leopoldo: Oikos, 2011. 
Elites militares, trajetórias e redefinições político-institucionais (1850-1930). Revista de Sociologia e Política, v. 16, p. 199-220, 2008.

A formação de um exército à brasileira: lutas corporativas e adaptação institucional. História (São Paulo), v. 29, p. 71-94, 2010.

SOUZA, A. B. de. Duque de Caxias: o homem por trás do monumento. Rio de Janeiro: Civilização Brasileira, 2008.

Hierarquia e mediação na trajetória do duque de Caxias. Militares e política (UFRJ), v. 5, p. 7-27, 2009.
Família de militares: o caso dos Lima e Silva. In: CASTRO, C. (Org.). A família militar no Brasil: transformações e permanências. Rio de Janeiro: FGV, 2018, p. 155-183.

. A serviço de Sua Majestade: a tradição militar portuguesa na composição do generalato brasileiro (1837-1850). In: CASTRO, C.; IZECKSOHN, V.; KRAAY, H. (Orgs.). Nova história militar brasileira. Rio de Janeiro: FGV/Bom Texto, 2004, p. 159-178.

WOLF, E. Relaciones de parentesco, de amistad y de patronazgo en las sociedades complejas. In: BANTON, M. (Org.). Antropología de las sociedades complejas. Madrid: Alianza Universidad, 1980, p. 19-39.

\section{Anexo}

Quadro 1 - Patentes dos oficiais militares Menna Barreto (incluindo Marinha e Aeronáutica)*

\begin{tabular}{l|l|l|l|l|l|l} 
Patente/Geração & $1^{\mathrm{a}}$ & $2^{\mathrm{a}}$ & $3^{\mathrm{a}}$ & $4^{\mathrm{a}}$ & 5 & $6^{\mathrm{a}}$ \\
Marechal & 01 & 03 & 04 & -- & -- & -- \\
General & -- & 01 & 02 & 06 & 09 & 01 \\
Brigadeiro & -- & -- & 01 & -- & -- & -- \\
Coronel & -- & 01 & 04 & 02 & 02 & 06 \\
Coronel Honor. & -- & -- & -- & -- & -- & 01 \\
Tenente-Coronel & 01 & -- & -- & 01 & -- & 05 \\
Major & -- & -- & 03 & 02 & 01 & 02 \\
Capitão & -- & 01 & 02 & 06 & 01 & 05 \\
Capitão Fragata & -- & -- & -- & 02 & -- & -- \\
Tenente & -- & -- & -- & 06 & 08 & 02 \\
Tenente Aviador & -- & -- & -- & -- & 02 & -- \\
Alferes & -- & 01 & 04 & -- & -- & -- \\
Cadete Exército & -- & -- & -- & -- & 01 & 02 \\
Cadete Aeron. & -- & -- & -- & -- & 01 & -- \\
Total Militares & 02 & 07 & 20 & 25 & 26 & 23 \\
Total Generalato & 01 & 04 & 07 & 06 & 09 & 01 \\
\hline
\end{tabular}

Fonte: Menna Barreto (1950, 1970).

\footnotetext{
* Patentes superiores: de major a marechal.
} 
RESUMO

Este artigo discute as condições de constituição de uma fração das elites militares a partir do estudo de grupos familiares cuja existência, reprodução e notabilização, ao longo de gerações, dependeram do Exército e de outras estruturas do Estado. A análise centra foco no grupo dos Menna Barreto e demonstra como o acesso privilegiado à carreira e valorização institucional de atributos angariados pelo grupo revelam o alto ajuste entre a oferta de oportunidades, no interior do serviço estatal a certas frações sociais, e as estratégias de reprodução que lograram acionar, perpetuando assim a própria instituição. É dada atenção especial aos condicionantes históricos de estruturação do Estado no período, e ao peso das estratégias matrimoniais e de notabilização eficazes na construção de patrimônios sociais erigidos em torno da ideia de "serviço ao Exército brasileiro".

\section{PALAVRAS-CHAVE}

Elites do Exército. Grupos familiares. Reprodução social. Menna Barreto.

\section{ABSTRACT}

This article discusses the forming of part of the military elites in Brazil. The research was based on the study of family groups whose existence, reproduction and notabilization throughout generations relied on the Army and on other structures of the State. Focusing on the Menna Barreto family, the analysis shows that a privileged access to the career and other key attributes amassed by the group reveal a high adjustement between opportunities within the State services, at the reach of only certain social fractions, and the strategies of reproduction that they put into action, thus perpetuating the institution itself. Special attention is given to the historical factors of State-buildion process in the period, as well as to the weight of effective marital and notabilization strategies in the making of social heritages erected around the idea of "servin the Brazilian Army".

\section{KEYWORDS}

Army elites. Family groups. Social reproduction. Menna Barreto 